\title{
Avaliação microbiológica de carne de charque produzida industrialmente
}

\section{Microbiological evaluation of industrially produced charqui meat}

\author{
Maria Rociene Abrantes', Ana Carina Praciano Sousa', Nikolay Kiev Saraiva de Araújo', \\ Êlika Suzianny de Sousa ${ }^{1}$, Adriene Rosceli Menezes de Oliveira', Jean Berg Alves da Silva ${ }^{1 *}$
}

RESUMO: O charque é um produto cárneo salgado e seco ao Sol obtido por desidratação da carne bovina, preservando-se, assim, por longo tempo. Apesar de passar por etapas que dificultam o crescimento de micro-organismos, pode ser contaminado durante o seu processamento. Dessa forma, objetivou-se avaliar microbiologicamente 25 amostras de charque de um frigorífico com serviço de inspeção estadual localizado no Rio Grande do Norte, Brasil. As amostras foram avaliadas quanto à contagem de estafilococos coagulase positiva, NMP de coliformes termotolerantes, Salmonella spp. e contagem de bactérias halofílicas. Avaliando a qualidade microbiológica da carne de charque, verificaram-se que cinco amostras (20\%) encontravam-se em desacordo com a legislação vigente (ANVISA) para análises de estafilococos coagulase positiva, apresentando uma variaçáo de 1,38 a 3,93 UFC/g; todas as amostras estavam em conformidade para coliformes termotolerantes. Quanto à determinação da Salmonella spp., verificou-se sua presença em sete amostras (28\%), e para bactérias halofílicas, uma média de 2,25 UFC/g. Assim, as carnes de charque apresentaram micro-organismos que comprometem a qualidade do produto e podem proporcionar risco ao consumidor.

PALAVRAS-CHAVE: manipulaçáo; Salmonella spp.; coliformes termotolerantes; higiene.

\begin{abstract}
Charqui is a salted and sun dried meat product, obtained by the dehydration of beef, thus being preserved for a long time. Despite going through steps which hamper microorganisms' growth, it can be contaminated during the processing stages. Therefore, this study was aimed at microbiologically evaluating 25 samples of charqui meat taken from a slaughterhouse in Rio Grande do Norte, Brazil. Samples were analyzed as to the counts of coagulase-positive staphylococci, the MPN of thermotolerant coliforms, the presence of Salmonella spp., and the counts of halophilic bacteria. By evaluating the microbiological quality of charqui meat, we observed that five samples (20\%) were off legal standards (ANVISA) as to coagulase positive staphylococci, with counts ranging from 1.38 to $3.93 \mathrm{CFU} / \mathrm{g}$, and all samples were within patterns for the thermotolerant coliform count. The presence of Salmonella spp. was observed in seven samples (28\%), and the average count of halophilic bacteria was of $2.25 \mathrm{CFU} / \mathrm{g}$. Thus, charqui meat presents microorganisms which compromise the quality of products and put the consumer's health at risk.
\end{abstract}

KEYWORDS: manipulation; Salmonella spp.; thermotolerant coliforms; hygiene. 
Charque é um produto cárneo salgado e seco ao Sol, típico do Brasil, conhecido também como carne do sertão, carne seca ou jabá (Sнimokomaki et al., 2006; Correia; Biscontini, 2003).

Atualmente, no Brasil, o principal público consumidor se concentra nas regióes Nordeste, Centro Oeste e Sul, sendo também consumido por populaçóes nordestinas fixadas na região Sudeste (Lira; Sнimokomaki, 1998).

Apesar de ser um dos produtos cárneos industrializados mais consumidos no país, sua expansão no mercado consumidor está longe de ser completamente explorada. Seu potencial ultrapassa o mercado interno, sendo um produto que náo requer a utilização da cadeia do frio para a sua preservação. É, portanto, uma fonte de proteína de origem animal para qualquer região do mundo, desprovida das dificuldades de refrigeração (Sнімокомакі et al., 2006), constituindo a base alimentar proteica de grande parte da população do Nordeste brasileiro, sendo típica do sertão e provavelmente tendo surgido em consequência das dificuldades de conservação da carne in natura nesta região (SouzA, 2007).

$\mathrm{O}$ uso de matéria prima de qualidade microbiológica inadequada, bem como condiçóes insatisfatórias de higiene durante e após o processamento do charque, pode resultar em produto com elevada carga microbiana (SнімокомакI et al., 2006).

Caso esses micro-organismos não sejam destruídos durante o processamento, podem multiplicar-se durante a produção, distribuição e comercialização dos alimentos, reduzindo a qualidade e aumentando o risco de provocar surtos (KunIGK; Almeida, 2001). Considerando a possibilidade de desenvolvimento microbiano neste produto cárneo bastante consumido, e pela sua relevante importância nutricional e econômica, objetivou-se avaliar a qualidade microbiológica da carne de charque produzida industrialmente sob serviço de inspeção estadual.

Foram coletadas no estado do Rio Grande do Norte, entre junho de 2009 e janeiro de 2010, 25 amostras de charque, prontas para comercialização, oriundas de um frigorífico com inspeção estadual (SIE). As amostras foram encaminhadas, devidamente acondicionadas, ao Laboratório de Inspeção de Produtos de Origem Animal (LIPOA), da Universidade Federal Rural do Semiárido (UFERSA), para serem submetidas às análises microbiológicas, com período em torno de quatro horas entre o momento da coleta e o início das análises. Logo após a recepção das amostras, eram realizadas as análises de acordo com as recomendaçôes da Instrução Normativa no 62, do Ministério da Agricultura, Pecuária e Abastecimento (Brasil, 2003) para estafilococos coagulase positiva, Número Mais Provável (NMP) de coliformes termotolerantes e Salmonella spp. Para pesquisa de bactérias halofílicas, seguiu-se a metodologia descrita por VANDERZANT; SPLITTSTOESSER (1992).

Foram pesados assepticamente $25 \mathrm{~g}$ de cada amostra de charque, sendo homogeneizadas em $225 \mathrm{~mL}$ de água peptonada $0,1 \%$ em "stomacher". A diluição obtida correspondeu a $10^{-1}$, a partir da qual foram obtidas as demais diluiçóes decimais até $10^{-3}$. Em seguida, foram submetidas às técnicas recomendadas para realização das análises.

Nas análises de estafilococos coagulase positiva, foram transferidas de cada diluição alíquotas de $1 \mathrm{~mL}$ para placas de Petri devidamente esterilizadas. Posteriormente, foram adicionados 15 mL de Ágar Baird-Parker enriquecido com solução de gema de ovo, com telurito 0,1\%. Logo após a secagem, as placas foram incubadas em estufas a $37^{\circ} \mathrm{C}$ por 48 horas para posterior contagem das colônias. Os resultados foram expressos em UFC/g.

Para quantificação de coliformes termotolerantes utilizou-se a técnica de diluições decimais em triplicata, iniciando com a prova presuntiva, a qual consiste na incubação das diluiçóes em caldo lauril sulfato de sódio contendo tubos de fermentação invertidos, incubados por 48 horas a $36^{\circ} \pm 1^{\circ} \mathrm{C} \mathrm{em}$ banho-maria. Os tubos com produção de gás foram inoculados em Verde Brilhante Bile Lactose a $2 \%$, a $36^{\circ} \pm 1^{\circ} \mathrm{C}$ por 48 horas. A partir de cada tubo positivo, foram inoculados em tubos contendo caldo E.C. e incubados a $45^{\circ} \mathrm{C} \pm 0,2^{\circ} \mathrm{C}$ por 48 horas para teste confirmativo de coliformes termotolerantes, sendo os resultados expressos em NMP/g.

$\mathrm{Na}$ determinação da ausência ou presença de Salmonella spp., utilizou-se a diluição correspondente a $10^{-1}$ incubados a $36^{\circ} \mathrm{C}$, por 20 horas, como pré-enriquecimento. Para o enriquecimento seletivo, foram utilizados os caldos tetrationato (TT), Rappaport (RR) e caldo selenito-cistina, incubados juntamente com alíquotas das amostras em tubos a $41 \pm 0,5^{\circ} \mathrm{C} \mathrm{em}$ banho-maria, com circulação contínua de água por 24 horas. A partir dos caldos seletivos de enriquecimento, foram repicados em placas contendo meio sólido seletivo, sendo incubados em estufa, por 24 horas, a $36^{\circ} \mathrm{C}$. Colônias suspeitas foram submetidas a provas bioquímicas para confirmação de Salmonella spp.

Para contagem de bactérias halofílicas transferiu-se $1 \mathrm{~mL}$ de cada diluição para placas de Petri estéreis, utilizando-se a técnica de semeadura em profundidade, adicionando, em seguida, $15 \mathrm{~mL}$ de Agar Plate Count (PCA), com 2\% de $\mathrm{NaCl}$, com incubação a $37^{\circ} \mathrm{C}$ por 24 horas. Os resultados foram expressos em Unidades Formadoras de Colônia (UFC)/g.

Avaliando a qualidade microbiológica da carne de charque ( $\mathrm{n}=25)$, verificou-se que cinco amostras (20\%) encontravam-se em desacordo com a legislação vigente, que estabelece a contagem máxima de $5 \times 10^{3} \mathrm{UFC/g}$ ou seu log 10 igual a 3,69 para análises de estafilococos coagulase positiva (BrasiL, 2001), apresentando uma variação de 1,38 a 3,93 UFC/g, valores expressos em $\log 10$ (Tabela 1 ).

Araújo et al. (2006), em estudo sobre a microbiologia do charque produzido em fábrica sob serviço de inspeção estadual em São Luís (MA), não detectaram crescimento de estafilococos coagulase positiva em nenhuma das sete amostras analisadas, e confirmaram presença de coliformes termotolerantes em duas delas. 
Tabela 1. Valores das análises microbiológicas de amostras de carne de charque de um frigorífico no estado do Rio Grande do Norte.

\begin{tabular}{|c|c|c|c|c|}
\hline & $\begin{array}{c}\text { Estafilococos } \\
\text { coagulase positiva } \\
\text { UFC/g }\end{array}$ & $\begin{array}{c}\text { Coliformes a } 45^{\circ} \mathrm{C} \\
\text { NMP } / \mathrm{g}\end{array}$ & $\begin{array}{c}\text { Bactérias halofílas } \\
\text { UFC/g }\end{array}$ & Salmonella sp/25 g \\
\hline Média & 2,6 & 0,36 & 2,25 & $7 / 25$ \\
\hline Mínimo & 1,38 & 0,30 & 1,47 & - \\
\hline Máximo & 3,93 & 1,17 & 5,24 & - \\
\hline $\begin{array}{l}\text { Legislação* (Amostras } \\
\text { fora do padrão) }\end{array}$ & $3,69(20 \%)$ & 3 (0\%) & - & Ausente (28\%) \\
\hline
\end{tabular}

*Agência Nacional de Vigilância Sanitária. Resolução da Diretoria Colegiada da Agência Nacional de Vigilância Sanitária, Regulamento Técnico sobre os Padrões Microbiológicos para Alimentos. RDC N 12, de 2 de janeiro de 2001.

Utilizando a mesma legislação como referência, os resultados das análises para coliformes termotolerantes neste estudo encontravam-se em conformidade, não sendo observado NMP acima de $10^{3}$ por grama de carne, ou seu $\log 10$ igual a 3 (BRASIL, 2001). A presença dessas bactérias em alimentos com quantidades elevadas indica a possibilidade de contaminação fecal e da presença de outros micro-organismos enteropatogênicos, bem como a qualidade higiênico-sanitária do produto insatisfatória (MOURA, 2011).

Os alimentos estão sujeitos à contaminação por micro-organismos, que são capazes de levar ao desenvolvimento de enfermidades, causando risco à saúde pública, seja desencadeada por micro-organismos patogênicos ou suas toxinas (Cunha Neto et al., 2002). Alguns alimentos estão frequentemente envolvidos em surtos de doenças, como leite e seus derivados, ovos, carnes e derivados. Entre os agentes causais mais envolvidos estão Staphylococcus aureus, Salmonella spp. e Escherichia coli (Germano; Germano, 2008).

A carne de charque pode servir de veículo para micro-organismos e causar surtos alimentares. Isso pode ocorrer devido ao processamento ao qual este produto é submetido, requerendo considerável manipulação, o que propicia a contaminação pelo $S$. aureus (Forsythe, 2002). Além disso, o S. aureus tem a capacidade de sobreviver em meio a dificuldades, e sua enterotoxina termoestável é capaz de resistir às técnicas convencionais de processamento térmico (PinTo et al., 1998).

Quanto à determinaçẫo da Salmonella spp., foi observada sua presença em sete amostras (28\%), sendo estas impróprias ao consumo humano, de acordo com o regulamento vigente que determina ausência de Salmonella spp. em 25 g (BrasiL, 2001).

A salmonelose é uma das zoonoses de maior importância no mundo, devido a perdas econômicas causadas na produção animal e por sua implicação em saúde pública (STRECK et al., 2007). $\mathrm{O}$ risco de desenvolvimento desta enfermidade pelo consumo de um alimento é influenciado por diversos fatores, entre eles, a quantidade de Salmonella spp. presente, as práticas de armazenamento e a manipulação de alimentos (Mürmann et al., 2007).
A presença desses micro-organismos em alimentos direcionados ao consumo humano, como o do presente estudo, é inaceitável, tendo em vista os riscos à saúde que estes causam. Isso se torna ainda mais preocupante considerando que este produto apresenta inspeção, realizada por órgãos oficiais. Segundo Bezerra et al. (2012), produtos como este devem apresentar condiçóes apropriadas de consumo, entretanto, a manipulação a que são submetidos propicia contaminação pela falta de aplicação das boas práticas.

Segundo Amson et al. (2006), práticas inadequadas que ocorrem durante o processamento dos alimentos permitem contaminaçôes, sobrevivência e multiplicação de micro-organismos patogênicos, sendo necessário melhorar os métodos de adoçáo e aplicação de programas de Boas Práticas de Fabricação. Dessa forma, será possível reduzir a incidência das doenças de origem alimentar.

Para as bactérias halofílicas, constatou-se em média 2,25 UFC/g (Tabela 1), com contagem variando de 1,47 a $5,24 \mathrm{UFC} / \mathrm{g}$. Os padróes microbiológicos atuais da ANVISA não fazem referência a limites de bactérias halofílicas para a carne de charque.

Para obter o charque, a carne passa por processamentos com o objetivo de promover a diminuição da atividade de água nos tecidos, com a adição de cloreto de sódio e a etapa de secagem ao Sol, dificultando, assim, o desenvolvimento de micro-organismos patogênicos (Gomez, 2006).

Entretanto, o sal utilizado durante o processamento na salga pode comprometer a qualidade final do produto, uma vez que o $\mathrm{NaCl}$ contaminado por bactérias halofílicas pode produzir nos alimentos pigmentação vermelha, sendo importante utilizar sal de boa qualidade (VAz et al., 2007).

As amostras de charque analisadas apresentaram micro-organismos que comprometem a qualidade do produto e causam risco ao consumidor, havendo a necessidade de readequação das Boas Práticas de Fabricação durante o processamento do produto. 


\section{REFERÊNCIAS}

AMSON, G.V.; HARACEMIV, S.M.C.; MASSON, M.L. Levantamento de dados epidemiológicos relativos à ocorrências/surtos de doenças transmitidas por alimentos (DTAS) no Estado do Paraná - Brasil, no período de 1978 a 2000 . Ciência e Agrotecnologia de Lavras, v.30, n.6, p.1139-1145, 2006.

ARAÚJO, R.S.; CALVET, R.M.L.; LACERDA, L.M.; LIMA, M.F.V.; SILVA, M.I.S.; LIMA, B.G. Microbiologia do charque produzido em fábrica sob serviço de inspeção estadual em São Luís - MA. Higiene Alimentar, v.20, n. 146, p.62-65, 2006.

BEZERRA, M.V.P.; ABRANTES, M.R.; SILVESTRE, M.K.S.; SOUSA, E.S.; ROCHA, M.O.C.; FAUSTINO, J.G.; SILVA, J.B.A. Avaliação microbiológica e físico-química de linguiça toscana no município de Mossoró, RN. Arquivo Instituto Biológico. v.79, n.2, p.297300,2012

BRASIL. AGÊNCIANACIONALDE VIGILÂNCIA SANITÁRIA. Resolução da Diretoria Colegiada da Agência Nacional de Vigilância Sanitária, Regulamento Técnico sobre os Padrões Microbiológicos para Alimentos. $\mathrm{RDC} \mathrm{N}^{\circ} 12$, de 2 de janeiro de 2001. Diário Oficial da República Federativa do Brasil, Poder Executivo, Brasília, 2001.

BRASIL. MINISTÉRIO DA AGRICULTURA. Instrução Normativa n 62 , de 26 de Agosto de 2003. Oficializa os métodos analíticos oficiais para análises microbiológicas para controle de produtos de origem animal e água. Diário Oficial da União, Brasília, p. 14,. Seção 1.

CORREIA, R.T.P.; BISCONTINI, T.M.B. Influência da dessalga e cozimento sobre a composição química e perfil de ácidos graxos de charque e jerkedbeef. Ciência e Tecnologia de Alimentos, v.23, n. 1, p.38-42, 2003.

CUNHA NETO, A.C.; SILVA, C.G.M.; STAMFORD, T.L.M. Staphylococcus enterotoxigênicos em alimentos in natura e processados no estado de Pernambuco, Brasil. Ciência e Tecnologia de Alimentos, v.22, n.3, p.263-271, 2002.

FORSYTHE, S.J. Microbiologia da segurança alimentar. Porto Alegre: Artmed, 2002. 424p.

GERMANO, P.M.L; GERMANO, M.I.S. Higiene e Vigilância Sanitária dos Alimentos. 3a ed. São Paulo: Manole, 2008. 986p.

GOMEZ, C.H.M.P. Jerkedbeef fermentado. Desenvolvimento de nova tecnologia de processamento. 2006. $101 \mathrm{f}$. Dissertação (Mestrado em Ciência de Alimentos do Departamento de Tecnologia de Alimentos e Medicamentos) - Universidade Estadual de Londrina, 2006.
KUNIGK, L.; ALMEIDA, M.C.B. Action of peracetic acid on Escherichia coli and Staphylococcus aureus in suspension or settled on stainless steel surfaces. Brazilian Journal of Microbiology, v.32, p.38-41, 2001

LIRA, G.M.; SHIMOKOMAKI, M. Parâmetros da qualidade da carne de sol e dos charques. Revista Higiene Alimentar, v.12. n.58, p.33-35, 1998.

MOURA, E.S.R. Aspectos sanitários dos abatedouros municipais do Estado do Rio Grande do Norte. $61 \mathrm{f}$. Dissertação (Mestrado em Ciência Animal do Departamento de Ciência Animal) - Universidade Federal Rural do SemiÁrido, 2011.

MÜRMANN, L.; SANTOS, M.C.M.; CARDOSO, M. Curvas de crescimento e destruição térmica de sorovares de Salmonellasp. isolados de linguiça frescal de carne suína. Acta Scientiae Veterinariae, v.35, n.3, p.309-313, 2007.

PINTO, M.F.; PONSANO, E.H.G.; FRANCO, B.D.G. M.; SHIMOKOMAKI, M. Controle de Staphylococcus aureus em charques (jerkedbeef) por culturas iniciadoras. Ciência e Tecnologia de Alimentos, v.18, n.2, p.200-204, 1998.

SHIMOKOMAKI, M.; OLIVIO, R.; TERRA, N.N.; FRANCO, B.D.G.M. Atualidades em ciência e tecnologia de carnes. São Paulo: Livraria Varela, 2006. 236p.

SOUZA, D.R.S. Aspectos industriais na produção de charque. 2007. Trabalho monográfico de conclusão do curso de Higiene e Inspeção de produtos de Origem Animal (TCC) - Universidade Castelo Branco, São Paulo, 2007.

STRECK, A.F.; VAZ, C.S.L.; MARKS, F.S.M.; OLIVEIRA, S.D.; CARDOSO, M.R.I.; CANAL, C.W. Análise do poder discriminatório da SE-AFLP para Salmonella Enteritidis frente a outras técnicas fenotípicas e genotípicas. Acta Scientiae Veterinariae, v.35, n. 1, p.73-78, 2007

VANDERZANT, C.; SPLITTSTOESSER, D.F. Compendium of methods for the microbiological examination of food. American Public Health Association, 1992.

VAZ, J.; LOPES, B.; SOUSA, J. Processamento de bacalhão salgado seco. Processamento Geral de Alimentos. Coimbra: Instituto Politécnico de Coimbra. Escola Superior Agrária, 2007. 